2

$$
\text { 章 }
$$

Thermal Model and Associated Novel Approach for Synchrotron Radiation Liner with End Cooling

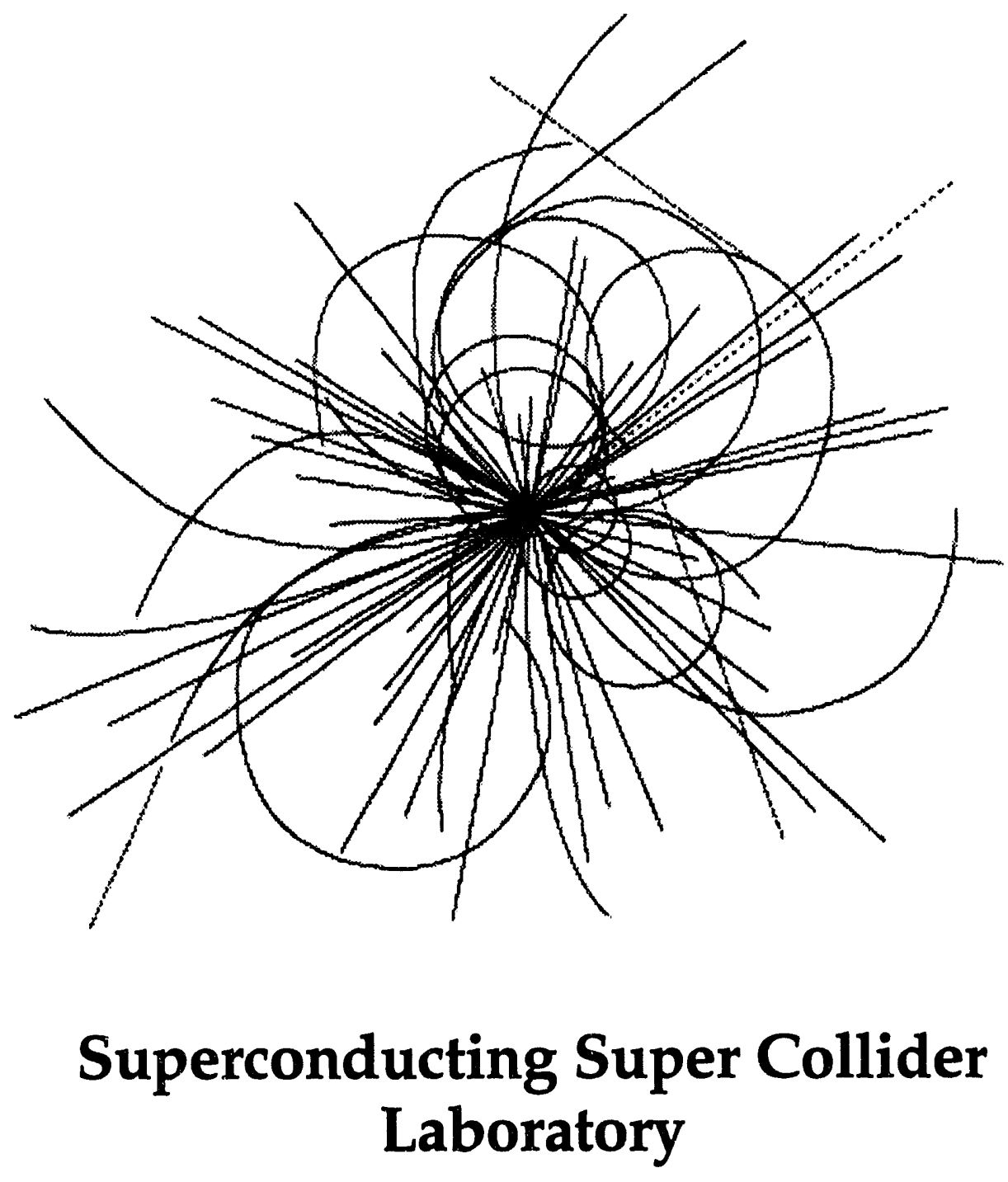

Conf $930511-231$ SSCL-Preprint-446 May 1993

Distribution Category: 400

Q. Shu

K. Yu

W. Clay

J. Maddocks

G. Morales

J. Zbasnik

\section{RECEIVED}

JUL 191993

OSTI 


\section{Disclaimer Notice}

This report was prepared as an account of work sponsored by an agency of the United States Govemment. Neither the United States Government or any agency thereot, nor any of their omployees, makes any warranty, express or implied, or assumes any legal liability c. responsibility for the accuracy, completeness, or usefulness of any information, apparatus, product, or process disclosed, or represents that its use would not infringe privately owned rights. Reference herein to any specific commercial product, process, or service by trade name, trademark, manufacturer, or otherwise, does not necessarily constitute or imply its endorsement, recommendation, or favoring by the United States Government or any agency thereot. The views and opinions of authors expressed herein do not necesserily state or reflect those of the United States Govemment or any agency thereof. 


\title{
Thermal Model and Associated Novel Approach for Synchrotron Radiation Liner with End Cooling*
}

\author{
Q. Shu, K. Yu, W. Clay, J. Maddocks, G. Morales, and J. Zbasnik
}

Superconducting Super Collider Laboratory ${ }^{\dagger}$

2550 Beckleymeade Ave.

Dallas, TX 75237

May 1993

*Presented at the 1993 IEEE Particle Accelerator Conference on May 17-20, Washington, D.C.

†Operated by the Universities Research Association, Inc., for the U.S. Department of Energy under Contract No. DE-AC35-89ER40486. 


\title{
Thermal Model and Associated Novel Approach for Synchrotron Radiation Liner with End Cooling
}

\author{
Quan-Sheng Shu, Kun Yu, Wayne Clay \\ Jim Maddocks, Gilberto Morales, and Jon Zbasnik \\ Superconducting Super Collider Laboratory* \\ 2550 Beckleymeade Ave., Dallas, TX 75237 USA
}

\section{Abstract}

An end-conductive cooling approach has been developed to reduce the radial space budget of a synchrotron radiation liner to permit the maximum possible liner tube inner diameter (ID). A thermal model has also been developed to analyze the thermal performance of such liners. This approach is found to be acceptable for a liner in a 5-m-long quadrupole magnet and 3-m-long spool piece, but not for a longer 15-m dipole. The heat transfer and temperature distribution were calculated respectively along the axis of two different liner models: $20 \mathrm{~K}$ and $80 \mathrm{~K}$ liner with different thicknesses $(0.5-2 \mathrm{~mm})$ of liner tubes and different emissivities $(0.05-0.3)$ of liner surface for a variety of magnets. The thermal model is also applied to the case of an $80 \mathrm{~K}$ liner connected directly to a $4 \mathrm{~K}$ beam position monitor (BPM). In order to utilize the end cooling, a good thermal joint and a compact heat exchanger are designed.

\section{INTRODUCTION}

A uniform and maximum possible liner inner diameter (ID) is needed due to: (1) particle beam commissioning, (2) particle beam dynamic stability, and (3) safety margin of impedance. However, the maximum liner ID is constrained by: (1) the available magnet beam tube inner diameter (ID), and (2) the minimum liner radial space. Using regular cooling, the minimum liner radial space is $6 \mathrm{~mm}$, and using end-conducting cooling, the radial space needs to be $3.5 \mathrm{~mm}$. The $80 \mathrm{~K}$ synchrotron radiation liner prototype was designed to be tested at the Superconducting Super Collider Laboratory (SSCL) Accelerator System String Test (ASST) facility. In the case of the $80 \mathrm{~K}$ ASST liner, the $25.3-\mathrm{mm}$ design was chosen for the maximum liner ID.

Since the magnet quench-induced Lorentz pressure on a CQM liner is much smaller than that on a CDM liner, the pure copper tube was chosen for the CQM liner material. The RRR and thickness of the copper tube must be of sufficient value due to both requirements: (1) resistance wall: conductivity $\times$ Thickness $>2 \times 10 \Omega^{-1}$, and (2) conducting heat transfer requirement. However, the RRR and thickness shall not be too large in order to reduce the Lorentz pressure. This paper will focus on a thermal model used to predict the thermal performance of an end-cooling liner for different cases.

\footnotetext{
* Operated by Universities Research Association, Inc., for the U.S Department of Energy under Contract No. DE-AC35-89ER40486.
}

\section{THERMAL MODEL FOR END- CONDUCTIVE COOLING}

An end-conductive cooling approach for the Spool Piece and CQM is shown in Figure 1. The $80 \mathrm{~K}$ GHe flows through a compact heat exchanger located at each end of the liner tube outside of the CQM cold mass. The rest of the liner tube is refrigerated by thermal conduction. A compact heat exchanger and a good thermal conducting joint is designed to utilize the end-cooling approach and to assure an easy assembly.

A thermal model to analysis the end conductive cooling was developed by $Q$. S. Shu and K. Yu [1] [2], assuming: $\mathrm{Q}_{\mathrm{s}}$ synchrotron radiation, $0.14 \mathrm{~W} / \mathrm{m} ; \mathrm{Q}_{\mathrm{L}}$ (heat leak through support)/2L; $\mathrm{Q}_{\mathrm{r}}$ (heat leak by radiation)/2L; $\mathrm{L}$, half length of the CQM or Spool Piece; $A$, the cross section area of the liner tuber; $\lambda(\mathrm{T})$, the heat conductivity; $\lambda(80)_{\mathrm{Cu}} \approx 5.50 \mathrm{~W}(\mathrm{~cm} . \mathrm{K})$; $\lambda(80)_{\mathrm{snl} \mathrm{stl}} \approx 0.045 \mathrm{~W} /(\mathrm{cm} . \mathrm{K}) ; \varepsilon_{1}, \varepsilon_{2}$ the emissivity.

$$
\begin{aligned}
& Q_{T}=\sigma A\left(T_{4}^{1}-T_{2}^{4}\right) \varepsilon_{1} \varepsilon_{2} /\left(\varepsilon_{1}+\varepsilon_{2}-\varepsilon_{1} \varepsilon_{2}\right) \\
& d Q_{c}=\left(Q_{s}-Q_{L}-Q_{r}\right) d X
\end{aligned}
$$

if $\quad q=\left(Q_{s}-Q_{L}-Q_{r}\right)$

$$
Q_{x}=-\lambda(T) A d T / d X
$$

and

$$
\begin{aligned}
Q_{x+d x}= & -\lambda(T) A d[T+(d T / d X) d X] / d X \\
& =-\lambda(T) A\left[d T / d X+\left(d^{2} T / d X^{2}\right) d X\right]
\end{aligned}
$$

we know $Q_{x+d x}=d Q_{c}+Q_{x}$

$$
\begin{aligned}
& d^{2} T / d X^{2}=-q /[\lambda(T) A] \\
& T(X)=-\{q /[2 \lambda(T) A]\} X^{2}+C_{1} X+C_{2}
\end{aligned}
$$

boundary conditions:

$$
T(X) \prime_{x=L}=80 \mathrm{~K} ; T(X) I_{x=-L}=80 \mathrm{~K}
$$

we have,

$T(X)=-\{q /\{2 \lambda(T) A]\} X^{2}+\{\varrho /[2 \lambda(T) A]\} L^{2}+80$

Using the model: 1) The temperature distribution along the liners as functions both of the emissivities and of the tube thicknesses were calculated. 2) The maximum $\Delta \mathrm{T}$ could be less than $5 \mathrm{~K}$ for Spool Piece liner, and $10 \mathrm{~K}$ for CQM. 3) $\mathrm{A}$ temperature difference between the Spool Piece pipe ends and the middle of the liner is $2 \mathrm{~K}$ when copper layer of $2 \mathrm{~mm}$ is used and $10 \mathrm{~K}$ when copper layer of $0.5 \mathrm{~mm}$ was used. 4) For $\mathrm{CQM}, \Delta \mathrm{T}$ of $6 \mathrm{~K}$ is obtained with copper layer of $2 \mathrm{~mm}$, and 

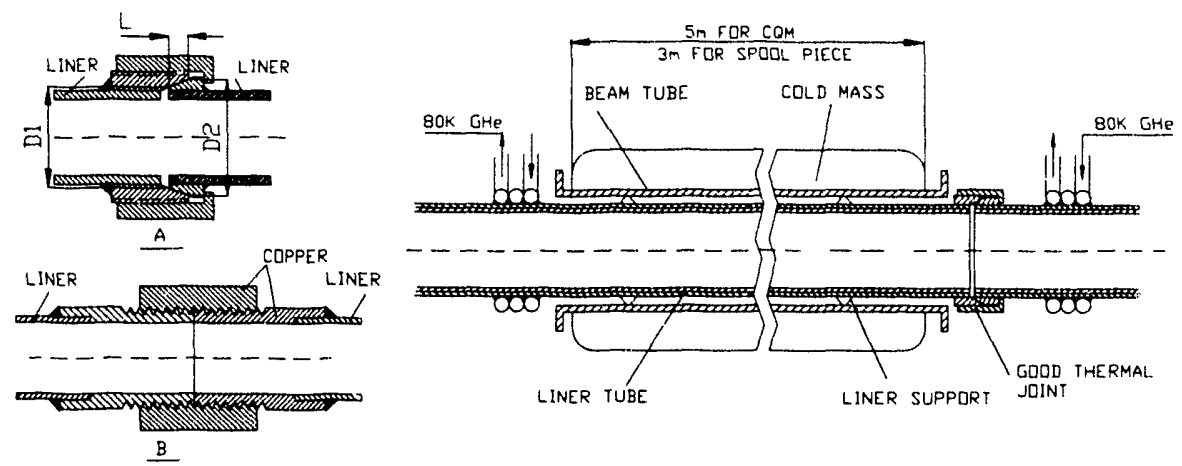

Figure 1. A schematic drawing of a liner with the end conducting cooling.

$26 \mathrm{~K}$ with copper layer of $0.5 \mathrm{~mm}$. 5) The correction of the effect of the magnetic field on copper thermal conductivity is considered. Figures 2, 3, and 4 show some of the calculated results.

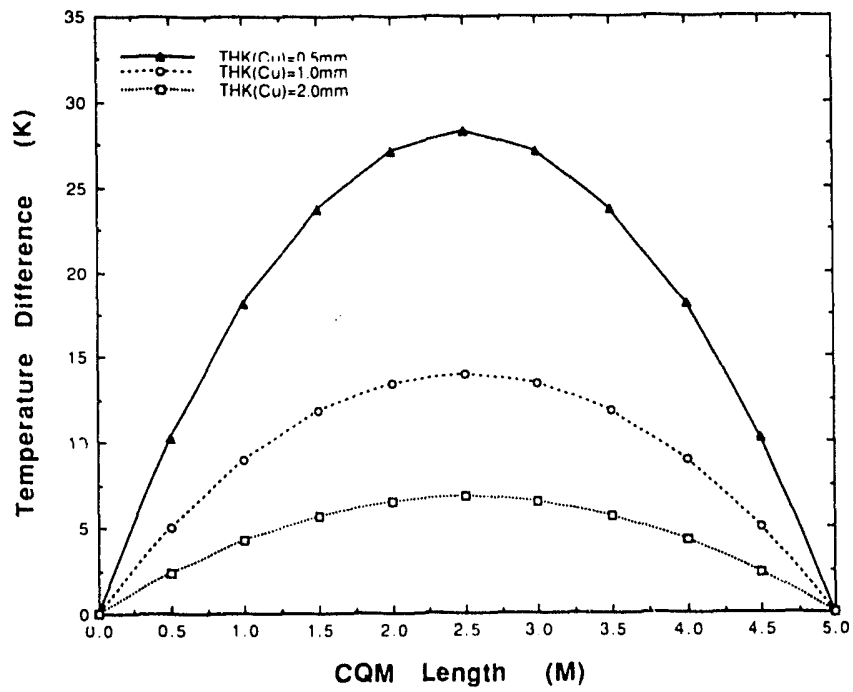

Figure 2. Temperature distribution of $80 \mathrm{~K}$ liners as function of liner tube thicknesses.

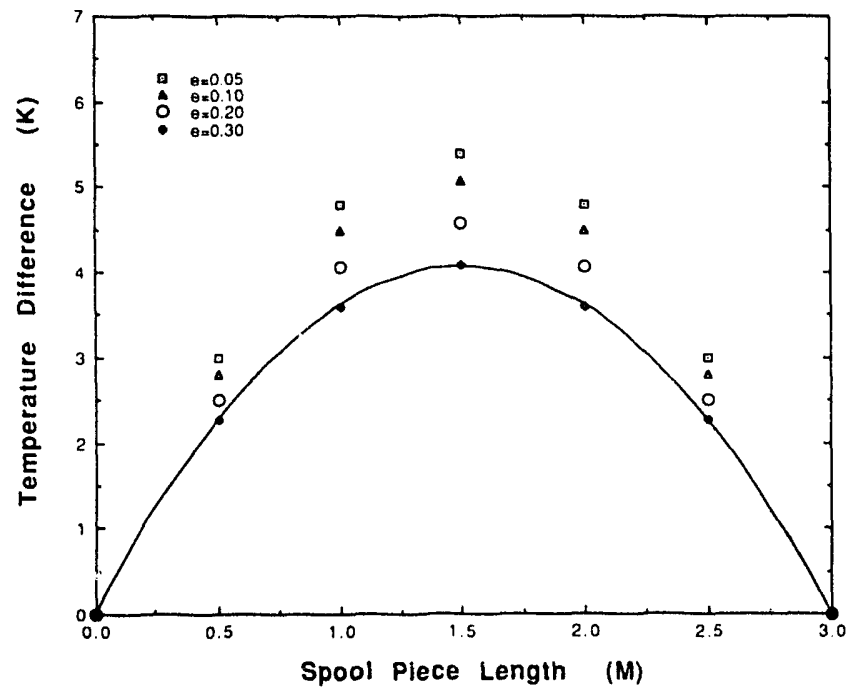

Figure 3. Temperature distribution of $80 \mathrm{~K}$ liners as function of liner surface emissivities.

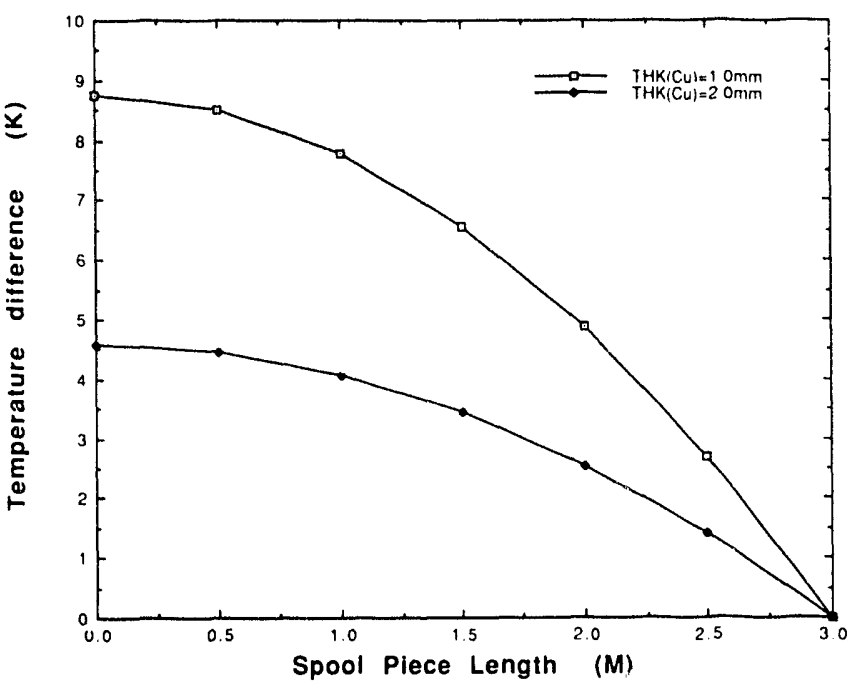

Figure 4. Temperature distribution of $20 \mathrm{~K}$ liners with only one end cooling.

\section{THERMAL MODEL FOR $80 \mathrm{~K}$ LINER WITH A 4 K BPM}

If a $4 \mathrm{~K} \mathrm{BPM}$ is used, the $80 \mathrm{~K}$ liner end-conductive cooling becomes more complicated, as shown in Figure 5. To reduce the heat leak through the copper liner tube from $80 \mathrm{~K}$ to $4 \mathrm{~K} \mathrm{BPM}$, a $10-20-\mathrm{cm}$-long piece of stainless steel tube is insert between the BPM and copper liner tube. The synchrotron radiation, the heat leak from liner to BPM, the heat leak from liner to $4 \mathrm{~K}$ beam tube, and the heat exchange between the liner and the $80 \mathrm{~K} \mathrm{GHe}$ must meest the law of conservation of energy.

First, we calculate a temperature distribut on along the stainless steel Liner tube;

when $0 \leq X \leq L$, we have,

$$
T_{s}(X)=-q X^{2} /\left(2 \lambda_{s} A_{s}\right)+S_{1} X+S_{2} .
$$

The temperature distribution along the copper tube shall satisfy $\mathrm{Eq}$.(2) if $L \leq X \leq L_{0}$.

$$
T_{c}(X)=-q X^{2} /\left(2 \lambda_{c} A_{c}\right)+C_{1} X+C_{2} .
$$

Eqs. (2) and (3) must meet the following boundary conditions: 


$$
\begin{aligned}
& T_{s}(0)=4 \\
& T_{c}\left(L_{o}\right)=80 \\
&\left.\lambda_{c} A_{c}\left\{\partial T_{c}(X) / \partial X\right\}\right|_{x=L}=\left.\lambda_{s} A_{s}\left\{\partial T_{s}(X) / \partial X\right\}\right|_{x=L} \\
& T_{s}(L)=T_{c}(L) \\
& \text { The } \mathrm{C}_{1}, \mathrm{C}_{2}, \mathrm{~S}_{1}, \text { and } \mathrm{S}_{2} \text { can be determined: } \\
& S_{2}=4 \\
& S_{1}=\left[\lambda_{c} A_{c} /\left(\lambda_{s} A_{s}\right)\right]\left[80+q L_{o}^{2} /\left(2 \lambda_{c} A_{c}\right)-\right. \\
&\left.q L^{2} /\left(2 \lambda_{c} A_{c}\right)+q L^{2} /\left(2 \lambda_{s} A_{s}\right)-4\right] \\
& \quad /\left[\lambda_{c} A_{c} L /\left(\lambda_{s} A_{s}\right)-L+L_{o}\right] \\
& C_{1}=\left[80+q L_{o}^{2} /\left(2 \lambda_{c} A_{c}\right)-\right. \\
&\left.q L^{2} /\left(2 \lambda_{c} A_{c}\right)+q L^{2} /\left(2 \lambda_{s} A_{s}\right)-4\right] \\
& /\left[\lambda_{c} A_{c} L /\left(\lambda_{s} A_{s}\right)-L+L_{o}\right] \\
& C_{2}= 80+q L_{o}^{2} /\left(2 \lambda_{c} A_{c}\right)-L_{o}\left\{\left[80+q L_{o}^{2}\right.\right. \\
& /\left(2 \lambda_{c} A_{c}\right)-q L^{2} /\left(2 \lambda_{c} A_{c}\right) \\
&\left.+q L^{2} /\left(2 \lambda_{s} A_{s}\right)-4\right] /\left[\lambda_{c} A_{c} L /\left(\lambda_{s} A_{s}\right)\right. \\
&\left.\left.-L+L_{o}\right]\right\} .
\end{aligned}
$$

Using Eqs. (2) and (3) the temperature distribution can be calculated and is shown in Figure 6.

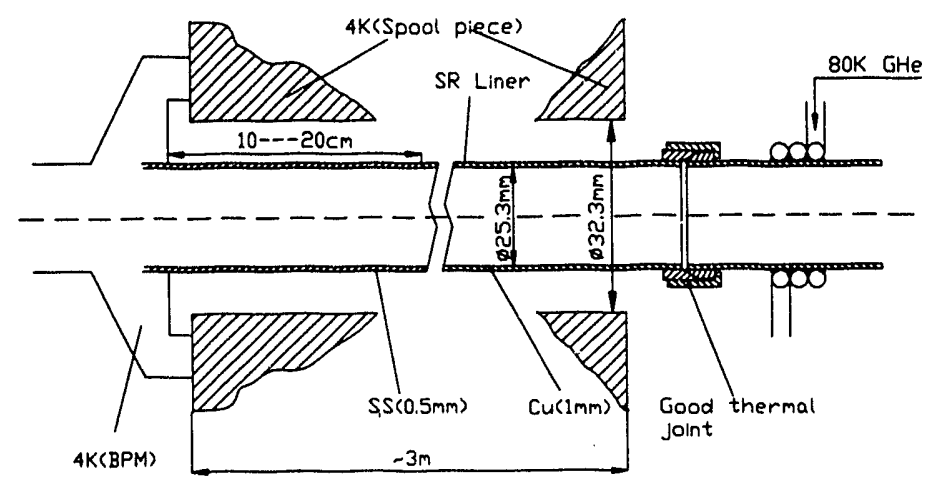

Figure 5. A schematic drawing of an $80 \mathrm{~K}$ liner with a $4 \mathrm{~K}$ BPM.

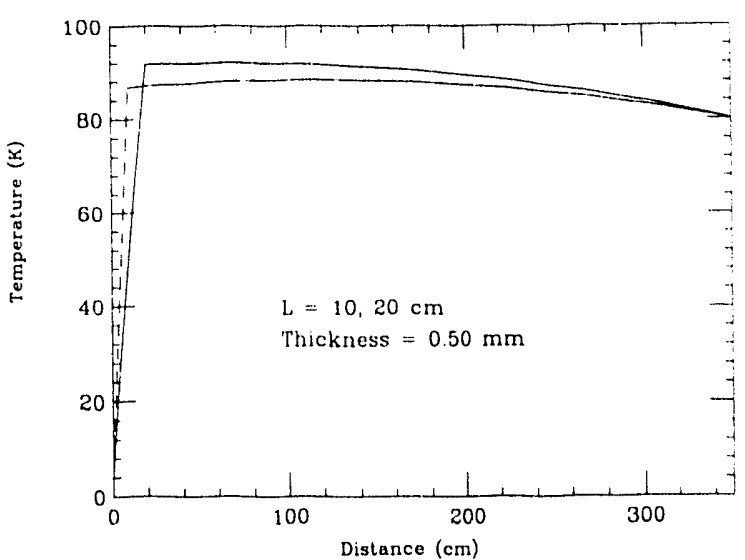

Figure 6. Temperature distribution along an $80 \mathrm{~K}$ liner with a $4 \mathrm{~K}$ BPM.

\section{GOOD THERMAL CONDUCTING JOINT}

A good thermal conducting joint concept, as shown in Figure 1, was proposed by Q. S. Shu and K. Yu. The joint makes liner assembly easier. Assume synchrotron radiation of a quadrupole to be $1 \mathrm{~W}$. The heat transferred at each liner end is $0.5 \mathrm{~W}$. If the pressure on the $\mathrm{Cu}-\mathrm{Cu}$ machined contact is $7 \mathrm{MPa}$, thermal conductance of the contact (at temperature range $5-25 \mathrm{~K})$ is $\mathrm{h}(\mathrm{T})=0.13 \mathrm{~T}\left(\mathrm{~W} / \mathrm{cm}^{2} \mathrm{~K}\right)$. The temperature across the joint $\Delta \mathrm{T}($ at $80 \mathrm{~K}) \leq 1 \mathrm{~K}$.

\section{COMPACT HEAT EXCHANGER}

To make end-cooling work, a compact heat exchanger with a length of less than $5 \mathrm{~cm}$ was developed. The total heat to be transferred by the heat exchanger is $Q=2 \mathrm{~W}$. Design parameters used were: Copper cooling tube $\mathrm{ID}=0.25 \mathrm{~cm}$, mass flow rate of the $80 \mathrm{~K} \mathrm{GHe}=\mathrm{dM} / \mathrm{dt}=0.25 \mathrm{~g} / \mathrm{s}$, temperature increase of GHe is $\Delta \mathrm{T}, \mathrm{R}_{\mathrm{e}}=\mathrm{GD} / \eta=31812, \mathrm{P}_{\mathrm{r}}=\eta \mathrm{C}_{\mathrm{p}} / \lambda=0.357, \mathrm{~h}=$ $0.023 C_{p} G^{0.8} \eta^{0.2} /\left(P_{r}{ }^{0.6} D_{e}{ }^{0.2}\right)=0.0345$. If three turns are used, $\mathrm{L}=28.75 \mathrm{~cm}, \Delta \mathrm{T}<1 \mathrm{~K}$.

\section{ACKNOWLEDGMENTS}

The authors sincerely thank A. Yucel, D. Clark, D. Martin, and W. Turner of the SSCL for their contribution to the work.

\section{REFERENCES}

[1] Q. S. Shu, Status Report on the ASST Liner System Design, SSCL-N-805, November, 1993.

[2] 80 K ASST liner Design Report, prepared by Q. S. Shu, (in preparation). 

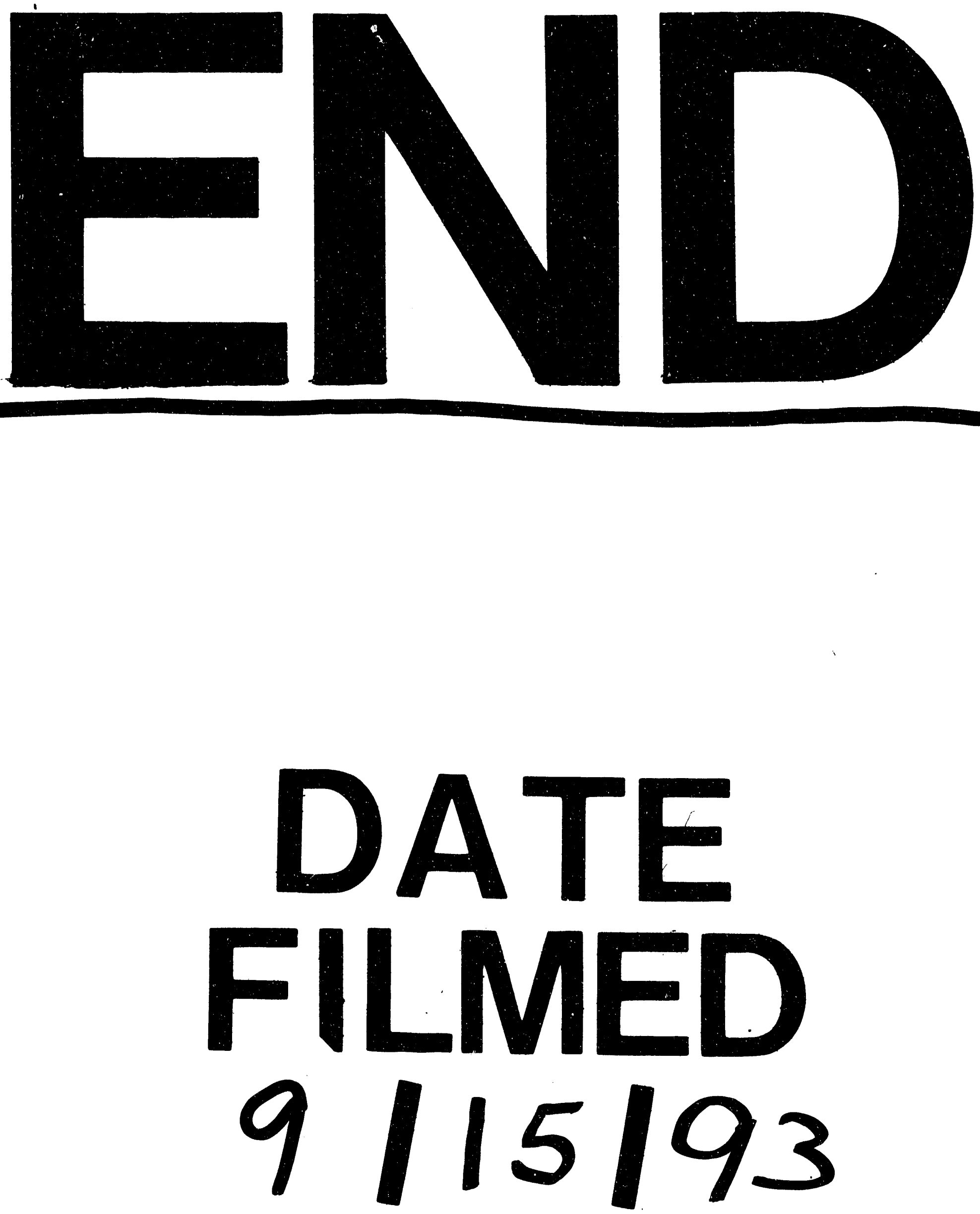
